\title{
BOCIO INTRATORÁCICO
}

\author{
INTRATHORACIC GOITER
}

${ }^{1}$ Médico internista.

Servicio de Medicina Interna Hospital General de Zona No. 29, Instituto Mexicano del Seguro Social. Ciudad de México.

Correspondencia a:

Nombre: Luis Guillermo Moreno Madrigal.

Correo electrónico: dr.luismoreno23@gmail.com.

Teléfono: +52-1-(55)-55-54-5645-67.

Palabras clave: Bocio, Glándula tiroides, Cirugía.

Keywords: Goiter, Thyroid gland, Surgery.
Procedencia y arbitraje: no comisionado, sometido a arbitraje externo.

Recibido para publicación: 21 Abril 2018

Aceptado para publicación:

14 de Julio 2018

Citar como

Rev Cient Cienc Med 2018; 21 (1):94-95

\section{PRESENTACIÓN DEL CASO}

Masculino de 45 años de edad, con hipertensión arterial como único antecedente relevante. Presentó disfagia alta, disfonía y disnea leve, de aproximadamente 6 meses de evolución, de inicio insidioso y empeoramiento progresivo, por lo que acudió a consulta. A la exploración física destacó aumento de volumen en cara anterior del cuello, de consistencia blanda y de gran tamaño, adherido a planos profundos, así como signo de Pemberton positivo (sugiriendo síndrome de vena cava superior). Se solicitó ultrasonido de cuello a la brevedad, detectándose bocio, eventualmente realizándose además tomografía de cuello y tórax donde se corroboró el diagnóstico de bocio con extensión intratorácica a mediastino superior, complicado con compresión faríngea, esofágica, laríngea, traqueal y de arterias y venas cérvico-mediastínicas. Contó con perfil tiroideo normal. Fué referido a tercer nivel de atención médica, donde se decidió su resección quirúrgica (tiroidectomía total con resección de la sección mediastínica), con mejoría clínica considerable. Se reportó bocio multinodular en estudio histopatológico.

\section{DESARROLLO}

El bocio intratorácico fue descrito por Haller en $1749^{1}$ y desde entonces ha recibido diversas denominaciones: retroesternal, subesternal, subclavicular, mediastínico, entre otras, ${ }^{1}$ considerándose sinónimos. ${ }^{2}$ Existen al menos 10 definiciones. ${ }^{2}$ Pueden ser primarios (sin conexión con la glándula cervical, originándose de restos tiroideos mediastínicos) o secundarios (prolongación tiroidea hacia el tórax), ${ }^{3}$ estos últimos representan la gran mayoría. ${ }^{2}$ Habitualmente los pacientes son eutiroideos. ${ }^{2}$

La prevalencia en Estados Unidos es del 0.02 - 0.5\%. ${ }^{1}$ Su principal variedad histológica es el bocio multinodular. ${ }^{3}$ Hasta $8 \%$ son malignos. ${ }^{2}$ El tipo cérvico-mediastínico es el más común (como el caso que se muestra). Tiene predominio femenino (de 3:1 a 5:1.3), surgiendo generalmente después de los 20 años de edad, siendo más frecuente entre la cuarta y quinta décadas de la vida. ${ }^{3} \mathrm{El} 70-80 \%$ son sintomáticos (masa cervical, disnea, estridor, disfagia, disfonía, hemorragia digestiva por várices esofágicas, síndrome de vena cava superior, ataques isquémicos transitorios y edema cerebral).'

El tratamiento de elección es el quirúrgico. ${ }^{3}$ Se han reportado complicaciones en el $1 \%$ de los procedimientos ${ }^{1}$, como hipoparatiroidismo, paresia de las cuerdas vocales, hematomas, ${ }^{3}$ infecciones, colapso traqueal, traqueomalacia, entre otros. ${ }^{1}$ 


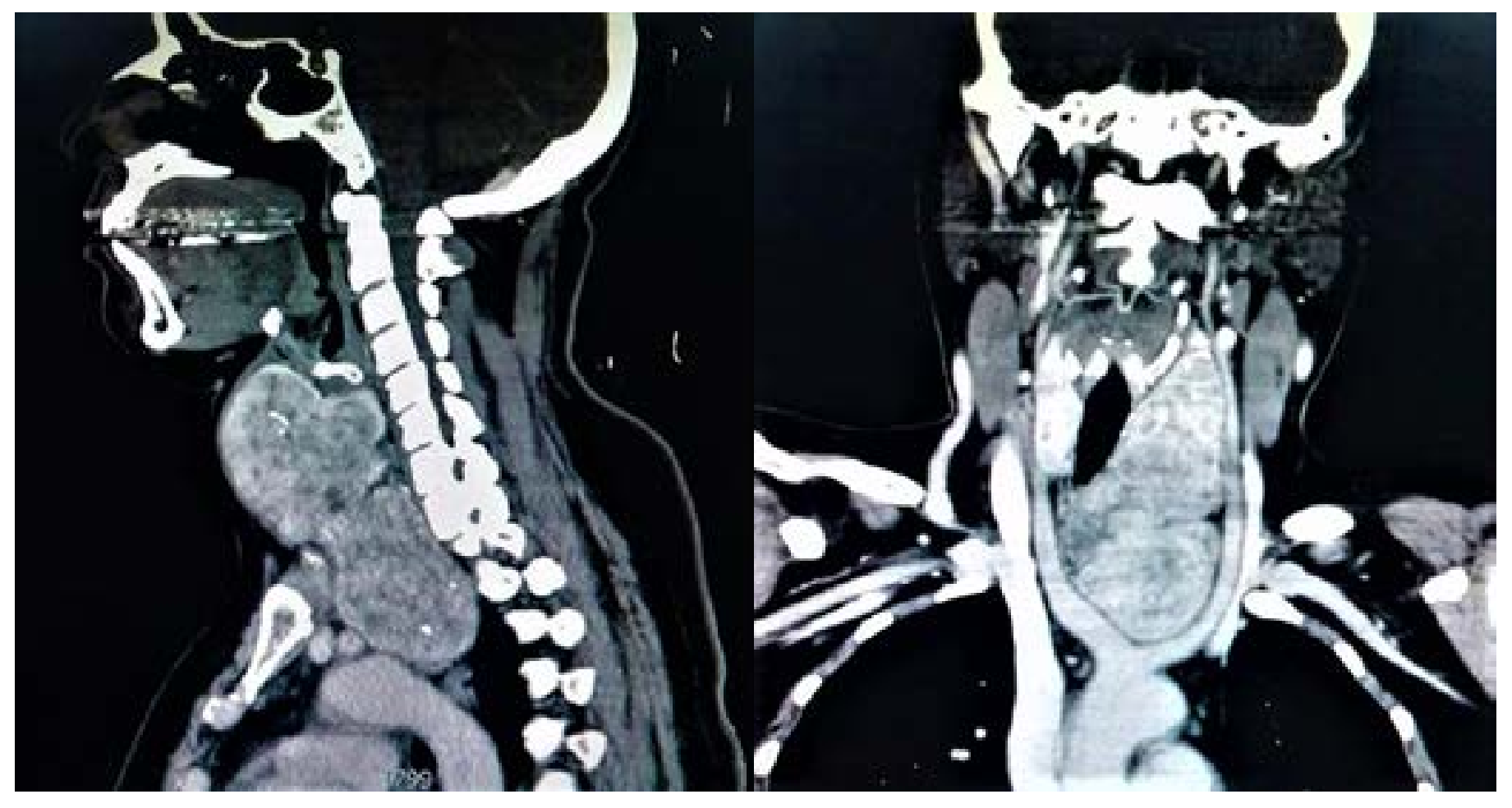

REFERENCIAS

1.De Aguiar-Quevedo K, Cerón-Navarro J, JordáAragón C, Pastor-Martínez E, Sales-Badia JG, GarcíaZarza A, et al. Bocio intratorácico. Revisión de la literatura médica. Cir. Esp. 2010; 88 (3): 142 - 145. 2,Al-Hashemy A, Gallo R, Shah MT, Al-Faifi A, Al-Amir A, AlShraim $\mathrm{M}$, et al. Giant intrathoracic goitre: The challenges. International Journal of Surgery Open 2016; 2: $6-10$. 3.Puerto-Lorenzo JA, Torres-Ajá L. Bocio endotorácico. Presentación de un caso. Revista Finlay 2013; 3 (2): 126 - 130. 